\title{
The burden of neovascular age-related macular degeneration: a patient's perspective
}

This article was published in the following Dove Press journal:

Clinical Ophthalmology

\author{
Kimberly L Spooner ${ }^{1,2}$ \\ Cleopatra T Mhlanga' \\ Thomas H Hong' \\ Geoffrey K Broadhead' \\ Andrew A Chang ${ }^{1,2}$ \\ 'Sydney Institute of Vision Science, \\ Sydney Retina, Sydney, NSW, Australia; \\ ${ }^{2}$ Save Sight Institute, University \\ of Sydney, Sydney, NSW, Australia
}

Correspondence: Andrew A Chang Sydney Institute of Vision Science, Sydney Retina, Level 13, Park House, I87 Macquarie Street, Sydney,

NSW 2000, Australia

Tel +6I 292213755

Fax +6I 292211637

Email achang@sydneyretina.com.au
Purpose: To quantify the burden and quality of life of patients and their caregivers in a cohort of patients with neovascular age-related macular degeneration (nAMD) in an Australian clinical setting.

Methods: A total of 103 patients undergoing anti-vascular endothelial growth factor (VEGF) therapy for $\mathrm{nAMD}$ were asked to complete questionnaires relating to the financial and time burdens of nAMD.

Results: All patients completed the questionnaires. Loss in productivity due to attendance of appointments was $4.4 \pm 1.7$ hours per month, with additional time lost by caregivers. Financial strain was incurred by direct medical costs associated with intravitreal assessment and injections at an average of AU $\$ 199.2 \pm \$ 83.1$ per month. Indirect costs incurred averaged $\$ 64.8 \pm \$ 79.7$ per month. Qualitative indirect costs due to loss of productivity for the patient, unpaid caregivers, and loss of productivity due to premature mortality were also a considerable burden. Overall mean Visual Function Questionnaire and EuroQol 5D-3L scores were correlated with visual acuity and demonstrated patients' subjective decline in quality of vision.

Conclusion: Management of nAMD carries a substantial burden on patients and caregivers. These results provide important information in understanding the effect of anti-VEGF therapy among patients with nAMD. Together with the quality-of-life burden on the patients, the management of nAMD has a significant societal impact.

Keywords: burden, treatment, anti-VEGF, age-related macular degeneration, Australia, patient perspective

\section{Introduction}

Age-related macular degeneration (AMD) is the leading cause of visual impairment among Australians aged $>60$ years. ${ }^{1}$ As of 2000, there were an estimated 23,000 Australians classified as blind from AMD according to the Blue Mountains Eye Study. ${ }^{1}$ The current prevalence of early AMD and intermediate AMD is $14.8 \%$ and $10.5 \%$ among Australians. $^{2}$ The disease is classified into two subtypes: neovascular and dry AMD. Dry AMD in its early stage is characterized by Drusen and pigment changes, having only minimal affects on vision. The latter stages include progression to geographic atrophy, leading to severe vision impairment and neovascular AMD (nAMD). nAMD is characterized by the presence of choroidal neovascularization and accounts for $90 \%$ of cases of severe vision impairment. ${ }^{3}$ Consequently, this results in a loss of central vision, visual distortion, and a loss of contrast and intensity of colors. ${ }^{4}$ These patients are likely to suffer from depression as a result of isolating themselves and disengaging from previously enjoyed activities and an increased need for care.$^{5-7}$ A study conducted in the UK reported a $43 \%$ prevalence of clinically significant depressive symptoms in $43 \%$ of those seeking help for low vision. ${ }^{6}$ Furthermore, the effect of nAMD results in poor 
mobility and limitations in daily activities as a consequence of loss of vision. nAMD has also been shown to have emotional and physical effects on caregivers, with many reporting feelings of sadness and uselessness. ${ }^{8,9}$ These impairments may adversely reduce quality of life (QoL) as a result of not being able to engage in everyday activities. ${ }^{10}$

Treatment is available for $\mathrm{nAMD}$ in the form of ongoing intravitreal injections of anti-VEGF agents, which can prevent severe vision loss. ${ }^{11,12}$ However, an important aspect is the patient's own opinion on the need for treatment and the burden of treatment with monthly or bimonthly intravitreal injections. ${ }^{11}$ In cancer research, it has been well documented that some older persons decline treatment due to the perceived gain in life expectancy, which does not outweigh the loss in QoL. ${ }^{13}$ Due to the increasing elderly population, evidence on the burden of AMD on the global health system is becoming increasingly important, as there are now proven therapies to treat visual impairment effectively or slow its progression. ${ }^{14}$ As such, resource allocation for the treatment and monitoring of potentially blinding conditions has expanded. ${ }^{15}$

Additionally, caregivers report that time taken off work for caregiving is costly and meant that they were unable to meet their personal and employment obligations. ${ }^{16}$ Recent advances in anti-VEGF therapy for nAMD treatment have aimed to reduce the treatment burden of disease and enable patients to improve their QoL by reducing treatment frequency. The burden on patients has been extensively researched, documenting the significant magnitude of medical and nonmedical costs among nAMD patients. ${ }^{17,18}$ However, the precise costs that anti-VEGF therapies impose on caregivers remain poorly defined.

The purpose of this study was to investigate the burdens associated with AMD treatment on patients and their caregivers, and to quantify the burden of AMD on visionrelated QoL. ${ }^{19}$ This information is important in managing patients, ensuring their QoL and independence is maintained. Furthermore, data relating to the impact on caregivers will help in understanding the support required from caregivers in assisting them in their role.

\section{Methods}

\section{Study design and sample}

A total of 103 consecutive patients with wet nAMD were recruited at a tertiary referral center to complete a survey over a 2 -week period. The questionnaire was administered by a single interviewer face to face with the patient and carer (if applicable). In total, 103 participants were recruited into a cross-sectional, noninterventional study, with one patient declining to participate. Participants were required to be aged $\geq 50$ years, currently receiving antiVEGF injections for the treatment of nAMD, and have a best-corrected visual acuity (BCVA) letter score of 25-70 ETDRS, Early Treatment Diabetic Retinopathy Study letters (Snellen equivalent of 20/30 to 20/320). BCVA is performed at every clinical visit using a standard Snellen chart at $6 \mathrm{~m}$. Patients with an acute illness or cognitive or other impairment were eligible if a caregiver was able to assist them in completing details required in the study material. The Karnofsky performance score was used to assess patients' ability to function, with a score $\geq 60$ deemed sufficient to be included in the survey. ${ }^{20} \mathrm{~A}$ caregiver was defined as someone that was providing assistance and support with everyday activities, free of charge without being a professional, or being part of a social support network.

Ethical approval from the University of Sydney local ethics committee was obtained and the study adhered to the tenets of the Declaration of Helsinki. Prior to the commencement of the study, written informed consent was obtained from participants. Demographic information was gathered from all participants to ensure that a broad selection of participants of various ages, anti-VEGF treatment regimens, and disease severity were included in the study.

\section{Questionnaires}

Participants were asked details of potential burdens suffered over the preceding 3-month period. This encompassed the number of visits, financial expenses related to their eye care and vision, as well as time, details of expenditure, who incurred the direct cost, and whether the costs were subsidized, and if so the amount and type of reimbursement received (Supplementary material). Additionally, the time spent on activities of daily living by caregivers was also gathered by the interviewer, such as household chores, administrative tasks, and leisure activities. Patient data, such as visual VA, previous treatment, and comorbidities, were transferred from the patient records to the questionnaire.

All participants completed the EuroQol (EQ) 5D-3L questionnaire to provide additional information on their health-related QoL status and to note if there was a correlation between the results on these questionnaires and the severity of diagnosis of nAMD. We based severity of nAMD on VA according to the ICD10 revision, Australian modification: low vision, $\mathrm{VA} \geq 35(\geq 6 / 60)$ and $<60$ letters $(<6 / 18)$; reduced vision, $\mathrm{VA} \geq 60(\geq 6 / 18)$ and $<70$ letters $(<6 / 12)$; mildly reduced vision to the Australian legal driving limit, $\mathrm{VA} \geq 70$, and $<85$ letters $(\geq 6 / 12$ and $<6 / 6)$.

The EQ 5D-3L is a self-reporting questionnaire. It consists of five health-rated aspects, each with three levels of 
severity (no problems, some problems, or a lot of problems). The health aspects refer to mobility, self-care, usual activities, pain, discomfort, anxiety, and depression. An index utility score can be derived from the responses, ranging from -0.59 for the worst possible health state to 1.00 for perfect health. ${ }^{21}$ A visual analogue scale is also included for individuals to rate their current health state on a scale ranging between 0 (worst health imaginable) and 100 (best health imaginable). ${ }^{22}$

Participants also completed the National Eye Institute (NEI) Visual Function Questionnaire (VFQ) 25 intervieweradministered questionnaire. The NEI VFQ25 is specifically designed to assess vision-specific function and health-related QoL. It is an interview-administered subjective measure comprising 25 questions querying patient difficulties in performing daily activities, such as reading newspaper print and driving a car with best-corrected level of vision with glasses or contact lenses. ${ }^{23}$ In addition, the questionnaire assesses an individual's general health, mental health, social functioning, and visual information relating to ocular pain, color vision, and peripheral vision. ${ }^{24}$

\section{Data management}

Financial data collected were calculated in Australian dollars. The burden on caregivers was calculated based on time spent (in hours), time lost from leisure activities, or time taken off from work to assist the patient with the treatment of nAMD. Direct costs were defined as medical and medication costs during the 3 -month period. These included consultations, intravitreal injection treatment, individual health services, copayments, vitamin supplements, and cost of visual aids. For each participant, inpatient, outpatient, prescription, and supplement costs were calculated. Indirect costs are an important part of the overall cost of nAMD to a patient and their caregiver. Indirect costs are usually made up of costs related to transport getting to appointments, parking fees, loss of productivity for the patient, unpaid caregiver assistance, and loss of productivity due to premature mortality.

\section{Statistical analysis}

Data were analyzed using SPSS version 24.0. Demographic and VA characteristics for patients were summarized with descriptive statistics. NEI VFQ25 subscale scores were computed according to published algorithms. ${ }^{24}$ Values ranged from 0 to 100 , with higher scores indicating better visual function and well-being, and are expressed as means $\pm \mathrm{SD}$. Correlations between variables were assessed with Spearman's $\rho$ to determine if level of vision impacted upon QoL variables. Internal consistency and reliability were assessed with Cronbach's $\alpha$ for the eight multi-item subscales of the NEI VFQ25. Linear regression was used to assess the effects of age, injections, and BCVA on mean VFQ score. A 95\% CI with 5\% level of significance was adopted, and thus $P<0.05$ was considered statistically significant.

\section{Results}

All patients were recruited from a private tertiary referral center, located in a metropolitan city center accessible by public transport network. The average age of the 103 participants was $81.4 \pm 8.9$ years, with a slight predominance of females (52\%). Baseline characteristics are shown in Table 1. The mean time of treatment was 12-149 months, and mean number of previous intravitreal injections administered was 53.5 \pm 32.9 . Twelve (11.5\%) participants received solely ranibizumab, nine $(8.7 \%)$ patients solely aflibercept, and the remaining $83(79.8 \%)$ were initially treated with ranibizumab and subsequently switched to aflibercept during the course of their treatment. The mean time interval between injections was $7.6 \pm 0.8$ weeks. Caregivers included children (41\%), spouses (44\%), and friends (15\%). A total of 26 $(25 \%)$ patients were diagnosed with nAMD in both eyes. Approximately 24 (23\%) patients had severe vision loss at the time of survey administration (BCVA <20/200), 51 (49\%) were pensioners, and 53 (51\%) nonpensioners. In Australia, a pensioner is classified as a person aged $>65.5$ years, with a single home-owning pensioner with assets worth $<\$ 250,000$ eligible for a full pension of $\$ 907.60$ per week and a homeowning couple with assets $<\$ 375,000$ eligible for the full pension of $\$ 684.10$ each per week.

Table I Demographics of patients and caregivers

\begin{tabular}{l|l|l}
\hline & Mean \pm SD & Range \\
\hline Patients, $\mathrm{n}$ & 103 & \\
Age, years & $81.4 \pm 8.9$ & $54.0-96.0$ \\
Male, $\mathrm{n}(\%)$ & $51(48)$ & \\
BCVA, ETDRS letters & $60.7 \pm 17.5$ & $20.0-85.0$ \\
CRT, $\mu \mathrm{m}$ & $320.6 \pm 173.6$ & $210.0-1,016.0$ \\
Duration of treatment (months) & $70.2 \pm 41.5$ & $12.0-149.0$ \\
Previous injections, $\mathrm{n}$ & $53.5 \pm 32.9$ & $5.0-136.0$ \\
\hline & $\mathbf{n}$ & $\%$ \\
\hline Caregivers & & \\
\hline Retired & 27 & 26 \\
\hline Employed & 66 & 64 \\
\hline Housewife/man & 10 & 10 \\
\hline Relationship to patient & & \\
\hline Spouse & 44 & 44 \\
\hline Child & 43 & 41 \\
\hline Others & 16 & 15 \\
\hline
\end{tabular}

Abbreviations: BCVA, best-corrected visual acuity; CRT, central retinal thickness; ETDRS, Early Treatment Diabetic Retinopathy Study. 


\section{Financial and time burdens}

Funding of the health system in Australia is a combination of government funding and private health insurance. Government funding is through the Medicare scheme, which subsidizes out-of-hospital medical treatment and funds free universal access to in-hospital treatment within a public hospital. Most patients had private health insurance (93\%), and the remaining patients were self-funded (7\%), with both groups eligible for the Medicare subsidy. The greatest financial burden incurred was direct medical costs (medical treatment and medication). For this purpose, patients spent on average $\$ 299.2 \pm \$ 83.10$ a month and had a minimum cost of $\$ 20$ and a maximum of $\$ 620$ per month. These costs excluded the Medicare rebate of $\$ 36.55$ for the doctor's consultation fee, which includes specialist assessment and advice. For those patients undergoing intravitreal therapy on an outpatient-clinic basis, Medicare provided a rebate of $\$ 255.65$ for the procedure.

Ranibizumab and aflibercept are subsidized by the government on the national Pharmaceutical Benefits Scheme and provided to the patient at a cost of $\$ 38.80$ (\$6.80 for pensioners), with the government absorbing $\$ 1,100$ of the cost per injection. Dietary antioxidants also form an important part of the treatment of those with AMD. Although evidence shows it is effective in those with intermediate AMD only, ${ }^{25} 37.5 \%$ of patients stated that they took an Age-Related Eye Disease Study formulation macular dietary supplement at a cost of $\$ 28.10 \pm \$ 4.80$ per month. Indirect medical costs (travel costs, parking fees) amounted to an average of $\$ 64.80 \pm \$ 79.70$ per month. Several caregivers indicated indirect costs due to lost productivity in the workplace, having to take considerable time off work in order to bring the patient in for monthly appointments and injections. Carers were typically a family member or friend, with some living in the same household as the patient.

The most significant barriers to treatment adherence identified were the frequency and travel times associated with intravitreal injections. Many patients acknowledged the high number of other medical appointments they must manage due to other comorbidities related to aging. The most common comorbidities were hypertension ( $\mathrm{n}=76,74 \%)$, osteoarthritis $(n=37,36 \%)$, and depression $(n=16,16 \%)$. Total appointments/injections within a 12 -month period were $10.4 \pm 0.8$, and the mean travel time for ophthalmic appointments was 1.2 \pm 0.7 hours in each direction.

The loss of productivity of the patient amounted to $4.4 \pm 1.7$ hours per visit, amounting to a cost of $\$ 186.30 \pm \$ 71.90$ among those still working. Furthermore, patients may need up to a day of recovery after an intravitreal injection, which results in further work-time loss among employed patients, as well as careers, who patients rely heavily on to get them to and from injection appointments. The caregivers reported the time they spent accompanying the patient to their medical appointments specifically for intravitreal injections took an average of $6.2 \pm 1.1$ hours per month, which equates to a loss of $\$ 262.45 \pm \$ 46.60$ in income based on the national average hourly wage. ${ }^{26}$ Additionally, caregivers reported the time given to various activities in the daily life of the patient. This included time spent on household assistance and such tasks as grocery shopping, amounting to $4.3 \pm 3.2$ hours per week or a cost of $\$ 782.10 \pm \$ 135.50$ per week. Table 2 summarizes direct and indirect medical costs.

\section{QoL}

Mean visual QoL assessed with the NEI VFQ25, was 64.8 \pm 19.7 . Table 3 shows scoring of the VFQ25 subscales in these patients. Scores among normal healthy controls have been shown to be around 80-90. Subscales that exhibited the lowest scores were general health $(48.8 \pm 33.9)$, distance activities (51.7 \pm 25.5$)$, and general vision (57.0 \pm 20.8$)$. In contrast, near activities (82.5 \pm 21.6$)$, vision-related dependency (80.0 \pm 25.1$)$, and peripheral vision (75.8 \pm 28.9$)$ were only slightly affected. Some of the subscales, in particular near activities, role difficulties, and dependence, had large ceiling effects where a substantial percentage of subjects $(50 \%)$ had the highest possible score (100), and few had the lowest subscale score of 0 . Subscale internal consistency estimates measured by Cronbach's $\alpha$ ranged from 0.53 to 0.95 . Five of the eight subscales with Cronbach's $\alpha \geq 0.70$ demonstrated strong internal consistency and reliability

Table 2 Direct and indirect medical costs

\begin{tabular}{l|l}
\hline & Mean \pm SD \\
\hline Direct medical costs & \\
Number of visits per year & $10.4 \pm 0.8$ \\
Monthly costs, AU\$ & $232.0 \pm 130.1$ \\
Medications/vitamins, AU\$ & $51.10 \pm 29.30$ \\
Assessment and intravitreal procedure, AU\$ & $199.20 \pm 83.10$ \\
Other treatment and consultations, AU\$ & $120.00 \pm 154.60$ \\
Annual mean cost, AU\$ & $2,784.00 \pm 1,560.20$ \\
Indirect medical costs & \\
Travel and parking costs, AU\$ & $64.80 \pm 79.70$ \\
Time spent per visit, hours & $4.4 \pm 1.7$ \\
Travel time per visit, hours & $2.4 \pm 1.6$ \\
Caregiver time spent accompanying patient & $6.2 \pm I . I$ \\
to appointment, hours & \\
Hours per week needing assistance & $4.3 \pm 3.2$ \\
Annual mean cost of caregivers, AU\$ & $5,333.58 \pm 2,184.20$ \\
\hline
\end{tabular}


Table 3 NEI VFQ25 scores

\begin{tabular}{l|l|l|l|l}
\hline Questions & $\begin{array}{l}\text { Score } \\
\text { (mean } \pm \text { SD) }\end{array}$ & Median & IQR & $\begin{array}{l}\text { Cronbach's } \\
\alpha^{\text {a }}\end{array}$ \\
\hline General health & $48.8 \pm 33.9$ & 50 & 25.0 & NA \\
General vision & $57.0 \pm 20.8$ & 60 & 55.0 & NA \\
Ocular pain & $57.5 \pm 28.9$ & 62.5 & 34.4 & 0.89 \\
Near activities & $82.5 \pm 21.6$ & 93.8 & 75.0 & 0.86 \\
Distance activities & $51.7 \pm 25.5$ & 41.7 & 33.3 & 0.62 \\
Social functioning & $57.9 \pm 25.9$ & 54.2 & 41.7 & 0.95 \\
Mental health & $68.8 \pm 24.2$ & 75.0 & 50.0 & 0.53 \\
Role difficulties & $75.0 \pm 32.2$ & 87.5 & 50.0 & 0.92 \\
Dependency & $80.0 \pm 25.1$ & 100 & 50.0 & 0.89 \\
Driving & $58.9 \pm 42.2$ & 58.3 & 50.0 & 0.53 \\
Color vision & $60.6 \pm 26.7$ & 62.5 & 50.0 & NA \\
Peripheral vision & $75.8 \pm 28.9$ & 83.3 & 58.3 & NA \\
Overall score & $65.7 \pm 21.5$ & 66.8 & 52.8 & 0.56 \\
\hline
\end{tabular}

Note: ${ }^{a}$ Cronbach's $\alpha$ can be calculated only for multi-item scales. Abbreviations: NEI VFQ, National Eye Institute Visual Function Questionnaire; NA, not applicable.

within this cohort of patients with nAMD. Males had slightly higher mean overall VFQ scores $(66.3 \pm 7.1)$ than females (64.6 $\pm 4.5, P=0.06$ ).

Mean QoL assessed by the EQ 5D-3L was $0.6 \pm 0.3$ and EQ visual analogue scale was 73.1 \pm 21.9 . There was little difference in scores between males and females $(0.6 \pm 0.3$ and $0.6 \pm 0.2$, respectively; $P=0.52)$ or median age $(P=0.74)$. Correlations between VFQ subscores and BCVA ranged from 0.3 to 0.7 , excluding those for general vision, social functioning, dependence, and role difficulties, which were negligible $(<0.1)$. Those with the highest correlation with BCVA were general health $(R=0.74)$, near activities $(R=0.52)$, and color vision $(R=0.84)$.

Correlations between duration of treatment and overall mean VFQ and EQ 5D scores were 0.8 and 0.7 respectively. Duration of treatment was correlated with vision $\left(R^{2}=0.8\right)$, while CMT was negligible $\left(R^{2}=0.2\right)$. Correlations between VFQ subscores and cost of treatment ranged from 0.2 to 0.9 . The highest correlations with cost were driving $(R=0.97)$ and mental health $(R=0.81)$. All other subscales were negligible. Table 4 demonstrates direct and indirect medical costs per month by VA subanalyses.

Table 4 Direct and indirect medical costs per month by visual acuity subgroups

\begin{tabular}{l|l|l|l}
\hline \multirow{2}{*}{ Visual acuity } & \multicolumn{2}{|l|}{ Direct costs (AU\$) } & $\begin{array}{l}\text { Indirect } \\
\text { costs (AU\$) }\end{array}$ \\
\cline { 2 - 4 } & Injection costs & Medications & Transport \\
\hline$\geq 70$ letters & $186.0 \pm 22.2$ & $58.9 \pm 19.4$ & $88.9 \pm 87.1$ \\
$60-70$ letters & $215.0 \pm 19.7$ & $78.2 \pm 54.7$ & $44.7 \pm 44.5$ \\
$\leq 60$ letters & $178.0 \pm 35.5$ & $62.9 \pm 57.3$ & $85.3 \pm 96.7$ \\
\hline
\end{tabular}

Univariate analyses of overall mean VFQ scores were associated with BCVA $(P=0.05)$ and total overall costs $(P=0.01)$. Multivariate regression analysis demonstrated BCVA was a significant predictor of mean VFQ score ( $P=0.05$ ) after adjustment for possible confounders of total number of injections administered $(P=0.07)$, age $(P=0.08)$, duration of treatment $(P=0.08)$, and direct medical costs $(P=0.04)$.

\section{Discussion}

The findings highlight the importance of the social and economic burden among patients with nAMD and their caregivers. According to the Australian Institute of Health and Welfare (2014) AMD accounts for 5\% of disabling conditions. ${ }^{27}$ Vision loss associated with AMD in Australia is estimated to be at a cost of $\$ 5.15$ billion per year. ${ }^{28}$ The advent of anti-VEGF therapy has brought with it a higher financial burden of treatment. Upon introduction in the USA, the Medicare payments more than doubled from 1994 to 2006, with the annual direct cost estimated to be US $\$ 5.75$ billion per year, ${ }^{29}$ with similar findings in the UK. ${ }^{15}$ In addition to direct and indirect medical costs, vision loss has a significant impact on productivity and patient QoL.

When ranibizumab was added to the Australian Pharmaceutical Benefits Scheme in 2007, it was estimated to cost between $\$ 15,000$ and $\$ 45,000$ per extra quality-adjusted life-year. ${ }^{28}$ However, direct health expenditure for AMD is only one component of the costs of AMD. The economic burden extends to personal expenses incurred by the patient, such as those arising from the need for mobility, low-vision aids, and modifications within the home. Cruess et al estimated productivity loss, aids and home modifications, and the value of lost well-being to be $\$ 4.4$ billion, $\$ 305$ million, and $\$ 11.7$ billion, respectively, among patients with vision loss in Canada in 2007, with the indirect cost per patient being $\$ 19,370$ annually. ${ }^{30}$ This imposes a significant financial burden not only to the patient but also among the wider community.

Furthermore, AMD has a significant impact on the social and economic participation of patients in society, eg, their ability to work and engage socially. ${ }^{28,31}$ This burden extends to social welfare systems, community services, carers, and patients' families, who for instance may need to take time off work to take them to appointments. ${ }^{16,27}$ Although the VFQ-subscale score for dependency was relatively high (80.0 \pm 25.1$)$, scores for driving and social functioning were considerably lower (58.9 \pm 42.2 and $57.9 \pm 25.7$, respectively), indicating some patients may underestimate their dependence 
on others and community services. In a study by Hong et al, the incidence of persons with visual impairment taking up community support services over a 5- to 15 -year period was $41.7 \%$, increasing to $61.9 \%$ with reliance on family members and friends. ${ }^{32}$

Questionnaire responses indicated that participants considered the cost of treatment a significant burden, as well as the time spent at each of the many needed monthly appointments. The relatively low VFQ scores may be representative of the profound impact of AMD on these patients' subjective appraisal of their condition. The multivariate regression analysis revealed that lower VA, longer duration of treatment, and older age were indicators of lower VFQ scores. Gohil et $\mathrm{al}^{33}$ also found that the level of burden reported by patients resulted from a combination of advanced age, greater visual impairment, and thus the type of assistance they required.

Furthermore, the results indicated that loss of caregiver time for bringing participants into appointments every 4-6 weeks was a significant burden. While the carers were not paid for providing support and assistance, it can be stated that this assistance is not free in an economic sense. Some caregivers stated that it meant a day's wages were lost, in addition to the extra responsibility taken to care for the participants with their daily activities. Time spent caring involves sacrificing time that could have been spent on paid work or leisure activities. As such, this support and carer assistance can be valued as the opportunity cost associated with the loss of economic resources and loss in leisure time valued by the carer, which are among similar findings in cohorts in Japan, the USA, and other Australian centers. ${ }^{16,17,31}$

Among participants who scored highly on anxiety and depression assessed with the EQ 5D-3L, the largest concern related to the participant's health and well-being. Patient compliance and continuance represent a significant burden on the patient and wider community, as is the issue in the treatment of many chronic diseases. ${ }^{34}$ Compliance and persistence with monthly anti-VEGF treatment can be specifically challenging, with compliance rates in the VIEW trials being $91 \%$ at month 12 and dropping substantially to $83 \%$ by month $24 .{ }^{35}$ Ceasing treatment for as little as 3 months can be detrimental in terms of maintaining vision, with a high risk of recurrence if treatment has been discontinued for 3 months. ${ }^{36}$

The main limitation of our study is the relatively small sample and specificity to our clinic, and it did not incorporate a wider range of patients from different ethnicities and centers. It is, however, important to emphasize that these patients received anti-VEGF treatment for AMD in a real-world clinical setting in Australia, where it is a common treatment option. The VFQ25 analysis was carried out using standard methods described by the NEI. ${ }^{24}$ A more appropriate method would be to use Rasch analysis, which eliminates floor and ceiling effects. ${ }^{37}$ Further limitations include the bias of subjective self-reported outcomes and recall bias, as patients may not remember direct personal costs after any subsidies. A larger sample could lead to more precise representations of the general population.

\section{Conclusion}

Management of nAMD carries a substantial burden to patients and their caregivers. These results provide important information in understanding the effect of anti-VEGF therapy among patients with nAMD. Together with the QoL burden on patients, the management of nAMD has a significant societal impact.

\section{Acknowledgment}

Financial support was provided by Bayer Corporation Global. The sponsor had no role in the design, conduct or analysis of this research.

\section{Disclosure}

AAC has acted as a consultant for Alcon, Bayer, and Novartis. None of the authors has any proprietary interest in any material or method presented. All authors certify that they have no affiliations with or involvement in any organization or entity with any financial interest (such as honoraria, educational grants, participation in speakers' bureaux, membership, employment, consultancies, stock ownership, other equity interest, expert testimony, or patent-licensing arrangements), or nonfinancial interests (such as personal or professional relationships, affiliations, knowledge, or beliefs) in the subject matter or materials discussed in this manuscript. The authors report no other conflicts of interest in this work.

\section{References}

1. Wang JJ, Foran S, Mitchell P. Age-specific prevalence and causes of bilateral and unilateral visual impairment in older Australians: the Blue Mountains Eye Study. Clin Exp Ophthalmol. 2000;28(4):268-273. Available from: http://onlinelibrary.wiley.com/doi. Accessed November 26, 2018.

2. Keel S, Xie J, Foreman J, van Wijngaarden P, Taylor HR, Dirani M. Prevalence of age-related macular degeneration in Australia: the Australian National Eye Health Survey. JAMA Ophthalmol. 2017;135(11): $1242-1249$.

3. Ferris FL, Fine SL, Hyman L. Age-related macular degeneration and blindness due to neovascular maculopathy. Arch Ophthalmol. 1984;102(11): $1640-1642$.

4. Arden GB, Wolf JE. Colour vision testing as an aid to diagnosis and management of age related maculopathy. Br J Ophthalmol. 2004;88(9): $1180-1185$. 
5. Slakter JS, Stur M. Quality of life in patients with age-related macular degeneration: impact of the condition and benefits of treatment. Surv Ophthalmol. 2005;50(3):263-273.

6. Nollett CL, Bray N, Bunce C, et al. High prevalence of untreated depression in patients accessing low-vision services. Ophthalmology. 2016;123(2):440-441.

7. van der Aa HP, Comijs HC, Penninx BW, van Rens GH, van Nispen RM. Major depressive and anxiety disorders in visually impaired older adults. Invest Ophthalmol Vis Sci. 2015;56(2):849-854.

8. Dawson SR, Mallen CD, Gouldstone MB, Yarham R, Mansell G. The prevalence of anxiety and depression in people with age-related macular degeneration: a systematic review of observational study data. $B M C$ Ophthalmol. 2014;14:78.

9. Senra H, Balaskas K, Mahmoodi N, Aslam T. Experience of AntiVEGF treatment and clinical levels of depression and anxiety in patients with wet age-related macular degeneration. Am J Ophthalmol. 2017; 177:213-224.

10. Hernandez Trillo A, Dickinson CM. The impact of visual and nonvisual factors on quality of life and adaptation in adults with visual impairment. Invest Ophthalmol Vis Sci. 2012;53(7):4234-4241.

11. Mantel I, Niderprim SA, Gianniou C, Deli A, Ambresin A. Reducing the clinical burden of ranibizumab treatment for neovascular age-related macular degeneration using an individually planned regimen. $\mathrm{Br} J$ Ophthalmol. 2014;98(9):1192-1196.

12. Emerson MV, Lauer AK. Current and emerging therapies for the treatment of age-related macular degeneration. Clin Ophthalmol. 2008;2(2):377-388. Available from: https://www.dovepress.com/ getfile.php?fileID=2926. Accessed November 26, 2018.

13. Puts MT, Tapscott B, Fitch M, et al. A systematic review of factors influencing older adults' decision to accept or decline cancer treatment. Cancer Treat Rev. 2015;41(2):197-215.

14. Wong WL, Su X, Li X, et al. Global prevalence of age-related macular degeneration and disease burden projection for 2020 and 2040: a systematic review and meta-analysis. Lancet Glob Health. 2014;2(2): e106-e116.

15. Pezzullo L, Streatfeild J, Simkiss P, Shickle D. The economic impact of sight loss and blindness in the UK adult population. BMC Health Serv Res. 2018;18(1):63.

16. Hanemoto T, Hikichi Y, Kikuchi N, Kozawa T. The impact of different anti-vascular endothelial growth factor treatment regimens on reducing burden for caregivers and patients with wet age-related macular degeneration in a single-center real-world Japanese setting. PLoS One. 2017;12(12):e0189035.

17. Prenner JL, Halperin LS, Rycroft C, Hogue S, Williams Liu Z, Seibert R. Disease burden in the treatment of age-related macular degeneration: findings from a time-and-motion study. Am J Ophthalmol. 2015; 160(4):725-731.

18. Bandello F, Augustin A, Sahel JA, et al. Association between visual acuity and medical and non-medical costs in patients with wet age-related macular degeneration in France, Germany and Italy. Drugs Aging. 2008;25(3):255-268

19. Buckle M, Lee A, Mohamed Q, et al. Prevalence and incidence of blindness and other degrees of sight impairment in patients treated for neovascular age-related macular degeneration in a well-defined region of the United Kingdom. Eye. 2015;29(3):403-408.
20. Mor V, Laliberte L, Morris JN, Wiemann M. The Karnofsky Performance Status Scale. An examination of its reliability and validity in a research setting. Cancer. 1984;53(9):2002-2007.

21. Dolan P. Modeling valuations for EuroQol health states. Med Care. 1997;35(11):1095-1108.

22. Ravens-Sieberer U, Wille N, Badia X, et al. Feasibility, reliability, and validity of the EQ-5D-Y: results from a multinational study. Qual Life Res. 2010;19(6):887-897.

23. Stelmack JA, Stelmack TR, Massof RW. Measuring low-vision rehabilitation outcomes with the NEI VFQ-25. Invest Ophthalmol Vis Sci. 2002;43(9):2859-2868.

24. Mangione CM, Lee PP, Gutierrez PR, et al. Development of the 25-item National Eye Institute Visual Function Questionnaire. Arch Ophthalmol. 2001;119(7):1050-1058.

25. Evans JR, Lawrenson JG. Antioxidant vitamin and mineral supplements for slowing the progression of age-related macular degeneration. Cochrane Database Syst Rev. 2012;11:Cd000254.

26. Average Weekly Earnings A. cat. no. 6302.0. 2017. Accessed 21 November 2017.

27. Welfare AIoHa. Australia's Health 2014. Canberra. 2014.

28. Deloitte Access Economics. Eyes on the Future: A Clear Outlook on Age-Related Macular Degeneration. Report prepared for the Macular Degeneration Foundation. October 2011. Available from: http://www. mdfoundation.com.au/LatestNews/MDFoundationDeloitteAccess EconomicsReport2011.pdf. Accessed August 23, 2018.

29. Rein DB, Zhang P, Wirth KE, et al. The economic burden of major adult visual disorders in the United States. Arch Ophthalmol. 2006;124(12): $1754-1760$

30. Cruess AF, Gordon KD, Bellan L, Mitchell S, Pezzullo ML. The cost of vision loss in Canada. 2. Results. Can J Ophthalmol. 2011;46(4): 315-318.

31. Boyle J, Vukicevic M, Koklanis K, Itsiopoulos C, Rees G. Experiences of patients undergoing repeated intravitreal anti-vascular endothelial growth factor injections for neovascular age-related macular degeneration. Psychol Health Med. 2018;23(2):127-140.

32. Hong T, Mitchell P, Burlutsky G, Fong CS, Rochtchina E, Wang JJ. Visual impairment and subsequent use of support services among older people: longitudinal findings from the Blue Mountains Eye Study. Am J Ophthalmol. 2013;156(2):393-399.

33. Gohil R, Crosby-Nwaobi R, Forbes A, Burton B, Hykin P, Sivaprasad S. Caregiver burden in patients receiving ranibizumab therapy for neovascular age related macular degeneration. PLoS One. 2015;10(6): e0129361.

34. Treharne GJ, Lyons AC, Kitas GD. Adherence to medication. N Engl J Med. 2005;353(18):1972-1974.

35. Droege KM, Muether PS, Hermann MM, et al. Adherence to ranibizumab treatment for neovascular age-related macular degeneration in real life. Graefes Arch Clin Exp Ophthalmol. 2013;251(5):1281-1284.

36. Vaze A, Fraser-Bell S, Gillies M. Consequences of long-term discontinuation of vascular endothelial growth factor inhibitor therapy in the patients with neovascular age-related macular degeneration. Acta Ophthalmol. 2014;92(8):e697-e698.

37. Dougherty BE, Bullimore MA. Comparison of scoring approaches for the NEI VFQ-25 in low vision. Optom Vis Sci. 2010;87(8): $543-548$. 


\section{Supplementary material}

Patient name:

Patient's date of birth:
Carer name:

(if applicable)

\section{Modified low-vision-costs record: instructions}

\section{Things to record}

In this record, "personal cost" means the costs TO YOU, NOT the total cost before you received the subsidy or discount. "Subsidy" refers to the government subsidy, such as when a healthcare card is used or a half-price taxi voucher, travel pass, or concession for public transport.

In the record, please fill in anything that is related to your vision impairment ONLY. This may include:

1. Medicines, eye-care products, and equipment you buy or hire

2. Health and community services you use related to your sight

3. Informal care you receive from your family, friends, or relatives due to your vision impairment

4. Travel costs associated with caring for your eyes

5. All other expenditure you feel you have to spend that people with normal vision do not need to spend.

\section{Costs associated with vision problems for patients and their carers}

\begin{tabular}{|l|l|l|l|l|}
\hline Amount (\$) & $\begin{array}{l}\text { Time spent } \\
\text { (hours, minutes) }\end{array}$ & $\begin{array}{l}\text { Details of } \\
\text { expenditure }\end{array}$ & $\begin{array}{l}\text { Who bore the cost? } \\
\text { (patient, carer, relative, etc) }\end{array}$ & $\begin{array}{l}\text { Subsidy (y/n) } \\
\text { (If yes, please specify amount and type) }\end{array}$ \\
\hline & & & & \\
\hline & & & & \\
\hline & & & & \\
\hline & & & & \\
\hline & & & & \\
\hline & & & & \\
\hline & & & & \\
\hline
\end{tabular}

Do you live at home or retirement village or other?

Do you live alone/with partner/with children/carer?

Do you come to appointments alone? Or with someone? Who?

How do you get to appointments? Taxi/drive/public transport/with carer?

Do you take vitamin supplements for your macular degeneration? 


\section{Publish your work in this journal}

Clinical Ophthalmology is an international, peer-reviewed journal covering all subspecialties within ophthalmology. Key topics include: Optometry; Visual science; Pharmacology and drug therapy in eye diseases; Basic Sciences; Primary and Secondary eye care; Patien Safety and Quality of Care Improvements. This journal is indexed on

Submit your manuscript here: http://www.dovepress.com/clinical-ophthalmology-journal
Dovepress

PubMed Central and CAS, and is the official journal of The Society of Clinical Ophthalmology (SCO). The manuscript management system is completely online and includes a very quick and fair peer-review system, which is all easy to use. Visit http://www.dovepress.com/ testimonials.php to read real quotes from published authors. 